\title{
The Descriptions of Phrasal Verbs in Language Reference Materials
}

\author{
Rafidah Kamarudin ${ }^{1 *}$, Ainul Azmin Md Zamin² \\ ${ }^{1}$ Academy of Language Studies, Universiti Teknologi MARA Negeri Sembilan, Kuala Pilah Campus, 72000 Kuala Pilah, Negeri Sembi- \\ lan, Malaysia \\ ${ }^{2}$ Department of English Language and Literature, International Islamic University Malaysia, Jalan Gombak, 53100 Kuala Lumpur, Malaysia \\ Corresponding Author: Rafidah Kamarudin, E-mail: fid@ns.uitm.edu.my
}

\begin{tabular}{l} 
ARTICLE INFO \\
\hline Article history \\
Received: May 19, 2018 \\
Accepted: August 18, 2018 \\
Published: November 01, 2018 \\
Volume: 7 Issue: 6 \\
Advance access: September 2018 \\
\hline Conflicts of interest: None \\
Funding: None \\
\hline
\end{tabular}

\begin{abstract}
Multi-word units like phrasal verbs (PVs) are very common in English, indicating their usefulness in everyday settings. Despite the importance of PVs in both written and spoken discourse, it was reported that language learners generally have great difficulties in understanding and using this linguistic form due to various factors. However, studies examining the treatment of PVs in language reference materials, which may also contribute to learners' difficulties in understanding PVs are still lacking. Thus, the present study investigates how language reference materials, in particular those commonly prescribed to Malaysian school learners, address and describe this very common and important linguistic feature. Secondary school prescribed textbooks and two learner dictionaries were examined. All sections in the textbooks and dictionaries entries that discuss the selected common PVs were analyzed. Descriptive analysis was conducted to examine how this particular language form is described by looking at the selection of PVs, as well as information provided with respect to PVs. Results of the present study have revealed a number of useful findings with regard to the selection and description of PVs in both reference materials which to date, have not been found in any other studies in Malaysia, to inform relevant parties for further actions.
\end{abstract}

Key words: Corpus, Multi-word Units, Phrasal Verbs, Language Reference Materials

\section{INTRODUCTION}

Phrasal verb (PVs) is generally defined as a combination of two lexical elements: a verb (V) and a particle (AVP), which carries a particular meaning (carry out=perform; look into=investigate; go up=increase). PVs are ubiquitous and very common in English - in formal or informal registers as well as in written and spoken discourse (De Cock 2005). It is believed that the use of PVs makes our speech sounds more natural in expressing certain ideas (Fletcher 2005).

Despite the importance of PVs in language learning, there is a general consensus that they are difficult for second language (L2) learners to master (Littlemore \& Low 2006; De Cock 2005). Cross-linguistic factors, such as the influence of learners' first language (L1) and the non-existence of PV structure in learners' L1s may affect learners' understanding of PVs, which may result in the avoidance of PVs (El-Dakhs 2016; Kamarudin 2013b). Apart from that, learners' lack of awareness of common collocates, regular patterns and usage, is also reported to lead to deviant or non-standard use of PVs by language learners (Littlemore \& Low 2006; Zarifi \& Mukundan 2014).

'Transitivity' and 'separability' of PVs elements are among other aspects of PVs that can cause further confusion for learners. While transitive PVs allow particle movement in which the lexical verb and the particle can be separated (e.g. He picked the phone up); intransitive PVs do not (e.g. He sat down). Learners may also avoid PVs due to their semantic complexity (Houshyar \& Talebinezhad 2012) as most PVs carry multiple meanings which can be literal or idiomatic. It is reported that ESL learners at all levels use less idiomatic PVs (Akbari 2009). Thus, due to the complex nature of the PV itself, language learners may find this linguistic form difficult to learn and understand.

As far as pedagogical aspect is concerned, it is often suggested that learners should be first introduced to the high frequency PVs rather than the less frequent ones (Gardner \& Davies 2007) as they are more useful to learners in the real world. In other words, the 'core sense' or most common and useful meanings of PVs should be the first sense to be taught and learned. This suggests that reference materials providers should take this fact into consideration in the selection of PVs to be included in school textbooks and learner dictionaries. However, studies examining the treatment of PVs in reference materials indicates that multi-word units like PVs receive less attention by dictionary providers in comparison to the L1 multi-word units (Alanaser 2010); and bilingual dictionaries also do not provide a large number of PVs 
meanings, do not sort meanings according to the frequency of occurrence, and do not provide more complete information with respect to PVs (Dezortová's 2010).

Taking these problems into account, the present study was carried out to examine how PVs are treated and addressed in the prescribed textbooks and learner dictionaries used by Malaysian school learners. Most importantly, to date, no local studies have been carried out with regard to the selection and description of PVs in these reference materials. To be more specific, the present study aims to determine whether these reference materials provide sufficient and appropriate information with respect to PVs (i.e. definitions and examples) and take into account the PVs 'frequency of occurrence' factor in order to help learners understand and be able to produce this language form appropriately.

\section{METHODOLOGY}

\section{Instruments}

Five standardized series of English language textbooks prescribed by the Ministry of Education Malaysia for all secondary schools in Malaysia and two bilingual dictionaries commonly recommended by teachers were selected in this study. The two learner dictionaries examined are Kamus Dwibahasa Longman (KDL), $2^{\text {nd }}$ edition (2009) and Kamus Dwibahasa Oxford Fajar (KDO), $4^{\text {th }}$ edition (2008). As the focus of the study is on PVs, all pages in the textbooks that discuss this linguistic feature were identified. Below is the distribution of pages in the textbooks specifically discussing PVs (Table 1).

All sections in the textbooks and entries in the dictionaries that discuss common PVs were manually analysed. Following this, descriptive analysis was conducted to examine how PVs are described in the reference materials. In addition to that, an analysis on the selection of PVs (i.e. inclusion of 'high frequency' or 'core phrasal verbs') was also carried out. Identification of 'high frequency' PVs was based on those listed in the Collins COBUILD Phrasal Verbs Dictionary (2007).

\section{RESULTS AND DISCUSSION}

\section{The Descriptions of PVs in School Textbooks}

\section{Definitions of $P V S$}

In general, the way PVs are described in school textbooks is rather surprising. First of all, the definition of PVs provided is too general and vague - in the Form 3 (F3) textbook it is defined as 'a combination of verb and preposition'- which is

Table 1. Distribution of PVs in textbooks

\begin{tabular}{lcc}
\hline Form & $\begin{array}{c}\text { Number of pages } \\
\text { discussing PVs }\end{array}$ & $\begin{array}{c}\text { \% of pages } \\
\text { discussing PVs }\end{array}$ \\
\hline 1 (F1) & $1 / 202$ & 0.5 \\
2 (F2) & $0 / 202$ & 0 \\
$3(\mathrm{~F} 3)$ & $5 / 216$ & 2.31 \\
$4(\mathrm{~F} 4)$ & $3 / 264$ & 1.14 \\
$5(\mathrm{~F} 5)$ & $2 / 248$ & 0.81 \\
\hline
\end{tabular}

clearly not true as learners may assume that all combination of verb and prepositions are PVs. Many of the most frequent prepositions do not function as particles and thus the combination cannot be universally categorized as PVs (e.g. look at, come from, look for, come with). In the Form 1 (F1) textbook, the vague definition of PVs as 'words that go together' without further explanations of the possibility of elements in PVs being separated, may result in the lack of understanding on the part of learners with respect to possible structures of PVs (e.g. pick up the phone, pick the phone up, pick it up).

In the Form 5 (F5) textbook, PVs are defined as "a category of verbs consisting of two or three words which have a particular meaning". This however, may imply that many other word combinations such as take place, have a shower, give a hand, spill the beans, kick the bucket, are also included in the category of PVs, which is clearly not true. Thus, clearer definitions should be presented to inform learners that PVs are not simply "a category of verbs consisting of two or three words which have a particular meaning"; rather, they are a combination of a V+AVP that carry a particular meaning.

Another finding is that all textbooks, and, in most cases, provide 'latinate' definitions or the one-word equivalent of PVs (e.g. put off-postpone, look $u p=$ check, give $u p=$ surrender, go $u p=$ increase). The purpose of providing such definition is perhaps that 'latinate' words are easier to learn, especially if they have cognate words in the learners' L1. For instance, Malay words, such as 'bajet', 'kopi', 'akaun', 'bas', 'motosikal', are derived from the English words budget, coffee, account, bus, motorcycle, respectively, and they seem to make more sense to learners. However, to provide a 'latinate' definition without information with respect to the context of use may lead to inappropriate use of PVs, as not all PVs can be an exact replacement for their one-word equivalents. For example, in 'The floor was slippery, so I fell down (dropped)', learners may assume that dropped is an exact replacement of fell down, and, therefore, can be used interchangeably regardless of context or register, which is semantically not true. While the use of fell down is certainly appropriate in the above context, the one-word equivalent dropped is not (*The floor was slippery, so I dropped). Similarly, PV called off is less formal in register and very common in spoken discourse while cancelled appears in more formal written discourse. This suggests that the provision of one-word equivalents needs to be further supplemented with other important information (i.e. usage, register) to avoid assumptions that both carry exactly the same meaning and can be used interchangeably.

\section{Provision of Examples}

Findings of the study also indicate that many examples of PVs provided in the F3 textbook are either in imperative (e.g. 'Hurry up!'/'Watch out!') or intransitive form ('.many people were trapped inside and could not get out'./'.soon many people began to join in'.). Surprisingly, there is no example of transitive PVs to inform learners on the 'separability' aspect PVs (object/particle movement). This may further convince learners that PVs are 'words that always go together' and cannot be separated, which is clearly not true for most transitive PVs. Therefore, it is not surprising that learners at 
a lower school level were found to have difficulties in producing the correct structure of wake up with Pronouns (Pro) and the non-occurrence of switch off in the V+Pro+AVP pattern (e.g. switch it off) as reported in Kamarudin's (2013) study. This suggests the importance of clear definitions and explanations with respect to the definition, 'separability' of PVs and good examples to be provided for students to avoid confusion and inappropriate usage.

Despite the above deficiencies, interestingly the Form 4 (F4) textbook provides information about the semantic features of PVs, which is very useful as learners can see the different types of PV (literal and non-literal). However, the choice of non-literal PVs in a more familiar context should also be considered. The use of put down (suppressed) in 'The rebellion was put down by the army' (pg 224) may not be very helpful and it is doubtful that learners are familiar with the context in which put down is used in the above sentence. In fact, the word 'rebellion' itself may sound strange to most learners. Instead, the non-literal meaning of go out associated with lights/fire (e.g. 'It would take more than 24 hours before the fire goes out'), pick up with habit/skills (e.g. I want to pick up as many skills as possible'),or take off with plane/s (e.g. 'the plane took off from Bangkok'), get off with bus/train/car (e.g. 'I had panicked and got off the train at the wrong station') would be more useful to learners, as they are very common and frequently used in everyday communication. As students were also reported to be unfamiliar with many non-literal PVs that are very common such as go up, pick up and get off in the above senses (Kamarudin 2013a), these PVs should receive equal attention by textbook writers.

\section{Frequency Occurrence' of PVS}

As far as the 'frequency of occurrence' factor is concerned, findings indicate that learners at all levels are presented with low frequency PVs. F1 learners for instance, are presented with low frequency PVs like dig up and dying out. Many of the PVs presented in the upper level textbooks are also low frequency PVs (e.g. put across, put by, get ahead, waste away), which are not very helpful to learners. Surprisingly, high frequency PVs which learners at a higher school level are not very familiar with and problematic for them (e.g. go out, come out, take out, take off) (Kamarudin 2013a) are not explicitly addressed in the textbooks. High frequency PVs should be presented to learners as they have greater 'utility' in everyday communication (Ellis 2001). PVs like take off (remove clothing; leave the ground and fly), pick up (take somebody in a vehicle), go off (stop working) and go down (decrease) should alternatively be considered as they are highly produced by native speakers, and therefore, more useful to language learners.

Thus, it is important for textbook writers to take frequency information into consideration in their decision of which PVs should be presented to learners at each level. It is often suggested that the most frequent PVs should be the first to be introduced to students rather than the less frequent ones (Gardner \& Davies 2007), and emphasis should be given to core meanings of PVs as they are more useful to language learners: this is what is lacking in the textbooks investigated.

\section{The Descriptions of PVs in Learner Dictionaries}

\section{Definitions of $P V S$}

With regard to learner dictionaries, similar findings were revealed. In defining PVs, the KDL dictionary also provides the L2 synonyms or one-word verb equivalents of a PV. Although to a certain extent, it is helpful for learners as they can get the meanings of a particular PV in both L1 and L2 simultaneously, learners will have the tendency to "stick to and use the "latinate" definition rather than the Anglo-Saxon phrasal verb, especially if it is a one-word definition" (Side 1990). This claim was further confirmed by Kamarudin (2013a) in her corpus analysis of PV pick up (to get better in health) for instance, in which she found no instance of pick up in this sense appears in the learner corpus. Instead, learners show great tendency to use the one-word verb recover (e.g. 'Izal and the girl was admitted for two days in the hospital and recovered very fast'). This is probably because the one-word synonym (i.e. recover) is easier to learn, and it also has an equivalent in learners' L1 (i.e. sembuh), thus it seems to make more sense to learners.

According to Parkinson (2001), providing learners with synonyms will allow them to decide whether a PV or a single-word equivalent is the more appropriate choice. This is perhaps true in the case of advanced or more proficient learners as they may be able to decide whether PVs or one-word verbs are more appropriate to be used in a particular context. On the other hand, beginners or learners at a lower school level may have difficulty in making an appropriate choice, as they are not aware of the context or register that influences the choice between a one-word equivalent and a PV. For instance, although resemble ('to be similar to someone or something else') is equivalent to take after, the PV take after is only used to refer to people in the same family who resemble each other; similarly, PV get up is appropriately used in 'What time did you get up this morning?' rather than 'What time did you rise this morning?'. Thus, providing PV synonyms to learners at a lower level may not be very helpful if they are not supplemented with clear examples. Examples are essential to illustrate differences in terms of usage and register in order to help learners in making appropriate choices. This will avoid those at a lower school level in particular, to assume that the one-word verb synonyms are an exact replacement of PVs and can be used interchangeably.

\section{Provision of Examples}

Another finding relates to the provision of examples in the learner dictionaries. As many English words including PVs are polysemous and have multiple meanings, dictionaries should provide examples to illustrate the context which creates the different meanings of a PV. However, it is very surprising that none of the dictionaries provides this. For instance, without any example to illustrate the different meanings of pick up (collect), learners may not be aware of the association of pick up in this sense with both animate and inanimate objects, as in 'pick up the rubbish' and 'pick up my daughter'. As the lexical verb pick is presented in the same entry, and the association of pick with inanimate ob- 
jects (e.g. flowers and fruits) is explicitly presented, it is not impossible that learners may assume that PV pick up can only be associated with inanimate objects. This is further supported by a large number of instances of pick up with inanimate objects rather than animate objects produced by learners as reported by Kamarudin (2013a).

Summers (1988) claims that "If they [students] do not get help over the collocations, typical context, and grammatical possibilities of the word, they may make errors". This suggests the importance of providing examples instead of just word meanings, so that learners are aware of the different contexts of use, common collocates, and grammatical patterns of a particular lexical item presented in a dictionary. Closer examination of the two dictionaries shows that none of them provide examples in context to illustrate the meaning and usage of PVs, and no information with respect to grammatical pattern (e.g. aspects related to transitivity and separability of PVs) is presented. As a result, this may lead to the non-standard use of many common PVs by language learners. PV wake up for instance, which is listed in the $\mathrm{KDO}$ but not in the KDL, is simply defined as 'terjaga/terbangun' in the learners' L1, without any example to inform learners of typical grammatical patterns, particularly when it involves pronouns. Thus, if learners refer to this dictionary, they may get the L1 definition of a PV, but not the rule with respect to object/particle movement, which is very important in learning and understanding PVs. This is another possible explanation to the inappropriate syntactic structure in the production of * 'wake up me' instead of 'wake me up' by learners (Kamarudin, 2013b).

\section{'Frequency Occurrence' of PVS}

Closer examination of the two dictionaries also indicates that neither of the publishers claim that their dictionaries are corpus-based and produced with the benefit of frequency counts, which are very helpful in identifying those PVs that are very frequent in native speakers' discourse, commonly used in everyday settings, and, therefore, most useful for learners. Poor selection will undoubtedly result in presenting less frequent and less useful lexical items, including PVs to learners. Thus, it is not surprising that many high frequency PVs (Gardner and Davies 2007) are not found in both dictionaries, instead, many low frequency PVs, which are of less 'utility' in the real world are presented to them. Table 2 summarizes the occurrence of the top 20 high frequency PVs listed by Garner and Davies (2007) in both dictionaries.

Analysis presented in Table 2 shows that the KDO has a slightly larger number of high frequency PVs compared to the KDL. Of all the 20 high frequency PVs, the KDO lists 12 of them, and less than half (8) are found in the KDL. This indicates that many of the high frequency PVs that are widely used by native speakers in everyday settings and thus very useful for learners are not listed in the two dictionaries investigated. Table 2 shows that PV go on is first in the list, and the Collins COBUILD Phrasal Verbs Dictionary provides 19 different senses of go on which suggests that this PV has a wide range of meanings and usage in everyday settings, and, therefore, is very useful for learners. However, this high fre-
Table 2. The occurrence of 20 high frequency PVs in the KDO and KDL

\begin{tabular}{lll}
\hline $\begin{array}{l}\text { Phrasal } \\
\text { verbs } \\
\text { (PVs) }\end{array}$ & $\begin{array}{l}\text { Kamus } \\
\text { dwibahasa } \\
\text { oxford (KDO) }\end{array}$ & $\begin{array}{l}\text { Kamus dwibahasa } \\
\text { longman (KDL) }\end{array}$ \\
\hline $\begin{array}{l}\text { go on } \\
\text { carry } \text { out }\end{array}$ & $\mathrm{X}$ & $\mathrm{X}$ \\
set up & $\mathrm{X}$ & $/$ \\
pick up & $/$ & $/$ (coded as noun) \\
go back & $\mathrm{X}$ & $/$ \\
come back & $\mathrm{X}$ & $\mathrm{X}$ \\
go out & $/$ & $\mathrm{X}$ \\
point out & $/$ & $\mathrm{X}$ \\
find out & $/$ & $\mathrm{X}$ \\
come up & $/$ & $/$ \\
make up & $/$ & $\mathrm{X}$ \\
take over & $/$ (coded as noun) & $\mathrm{X}$ \\
come out & $/$ & $\mathrm{X}$ \\
come on & $\mathrm{X}$ & $\mathrm{X}$ \\
come in & $\mathrm{X}$ & $\mathrm{X}$ \\
go down & $\mathrm{X}$ & $\mathrm{X}$ \\
work out & $/$ & $/$ \\
set out & $/$ & $/$ \\
take up & $/$ & $\mathrm{X}$ \\
get back & $\mathrm{X}$ & \\
\hline
\end{tabular}

quency PV is not listed in both dictionaries under investigation. Among the high frequency PVs with the headword go (go on, go back, go out, go up, go off, go in, go round, go over, go through, and go along) surprisingly, go over is the only $\mathrm{PV}$ listed in the KDL, and only three appear in the KDO - go out, go round, and go up. Similarly, out of 12 high frequency PVs with the headword come, PV come along is the only one listed in the KDL, together with another low frequency PV (i.e. come by). This suggests that many high frequency PVs which are problematic to learners are not listed in the KDL.

Further analysis related to the 'frequency of occurrence' has also revealed that a number of core meanings of high frequency PVs are not provided. One possible explanation is perhaps that, most often, the core meanings of PVs are very transparent and can be easily understood by learners simply by combining the meanings of each individual unit. However, it was reported that learners still have problems in using core meanings of high frequency PVs, such as come out, go out, fall down, take off (Kamarudin, 2013a) indicating that they should also receive equal attention in learner dictionaries. In the case of get off, for instance, it is rather surprising that the KDO only provides one meaning, terlepas tuduhan/dakwaan (to receive only a small punishment after doing something wrong), which is clearly not a core meaning of get off. On the other hand, the core meaning of get off (to leave a bus/train), which is very common in native speakers' discourse and more useful to learners, is not listed in the KDO. Similarly, the core meaning of go out (to leave a place/building) is also not given in the KDO.

Apart from that, findings also indicate that various types of 'lexical phrase', such as compounds, collocations, idioms, PVs, prepositional verbs, are listed together in the same entry. For instance, in the KDO, under the headword 
go, a learner may find a compound (go-cart), prepositional verb (go for), PV (go out, go up), and phrasal prepositional verb (go back on), and other common phrase (on the go). Similarly, collocations (take care of, take part, take place), PVs (take after, take down, take off), and other common phrases (take a bite, take a break) are listed together in the same entry in the KDL, under the head word take. There is no indication provided to inform learners of their differences.

As far as different types of word combination is concerned, it may not be necessary to highlight their differences if the purpose of a dictionary is merely to assist learners in 'decoding' rather than 'encoding' activities. However, if it is to be regarded as learning aid to improve fluency in the target language, clearly, further information concerning the differences is needed. Thus, having separate sections on PVs and other 'lexical phrases' might be more helpful for learners. Alternatively, a specialized bilingual PV dictionary with relevant information, such as examples to illustrate various core meanings, usage and grammatical patterns may also aid the learners' fluency in the target language. As stated earlier, with the limited period of learning English in classrooms, it is quite impossible for language teachers to discuss PVs in depth. However, with the help of more systematic and comprehensive dictionaries, learners would at least be aware of other important information with respect to PVs not addressed in classrooms.

\section{CONCLUSION}

In brief, the above analysis has revealed that both the school textbooks and learner dictionaries under investigation do not treat PV appropriately and adequately as an important language form. There is only a small section in the textbooks discussing PVs. Many of the PVs presented to learners are also not carefully defined and clearly explained with good examples of PVs. The selection of PV items to be included in the reference materials seems to be highly subjective, and mainly based on writers' intuition and common sense, rather than authentic language data (i.e. corpus-based frequency counts). In other words, PVs are presented to learners without sufficient consideration as to their frequency of occurrence in real life situations. It is important for learners to be presented with high frequency PVs as there is a high possibility that they will encounter such PVs more frequently in the future. This would help them to understand PVs better, and eventually, be able to use them appropriately in their written or spoken discourse. This suggests that a systematic selection of a 'core of phrasal verbs' is necessary to ensure learners are presented with PVs that are most useful for them in the world outside the classroom.

Thus, reference material providers in Malaysia in particular, should give a better treatment to this important language feature. They should be more careful with the information provided (i.e. definitions and examples), and the selection of PVs to be included (i.e. 'frequency occurrence' of PVs) in order to avoid unnecessary confusion and loss of time for both teachers and learners.

\section{REFERENCES}

Akbari, O. (2009). A Corpus Based Study on Malaysian ESL Learners' Use of Phrasal Verbs in Narrative Compositions. $\mathrm{PhD}$ thesis. Universiti Putra Malaysia.

Alnaser, M. (2010). Multi-word Items in Dictionaries from a Translator's Perspective. PhD thesis. Durham University.

Collins COBUILD Dictionary of Phrasal Verbs ( $2^{\text {nd }}$ edition). (2002). United Kingdom: Harper Collins Publishers.

De Cock, S. (2005). Learners and phrasal verbs. Macmillan Phrasal Verbs Plus. Oxford: Macmillan Publishers Limited. LS 16-LS20.

Dezortová, M.J. (2010). Phrasal Verbs and Their Translations into Czech (A corpus-based study). Master's Diploma Thesis. Masaryk University.

El-Dakhs, D.A.S. (2016). The Lexical Knowledge and Avoidance of Phrasal Verbs: The Case of Egyptian Learners of English. International Journal of Applied Linguistics \& English Literature, 5(1), 132-144.

Ellis, N. C. (2002). Frequency effects in language acquisition: A review with implications for theories of implicit and explicit language acquisition. Studies in Second Language Acquisition, 24, 143-188.

Fletcher, B. (2005). Register and phrasal verbs. Macmillan Phrasal Verbs Plus. Oxford: Macmillan Publishers Limited. LS 13-LS15.

Gardner, D. and Davies, M. (2007). Pointing Out Frequent Phrasal Verbs: A Corpus-Based Analysis. TESOL Quarterly, 41(2), 339-359.

Houshyar, S. and Talebinezhad, M. (2012). Study on Avoidance Behaviour among Persian EFL Learners: Phrasal Verbs in Focus. Greener Journal of Educational Research, 3(6), 238-248

Kamarudin, R. (2013a). A study on the use of phrasal verbs by Malaysian learners of English. $\mathrm{PhD}$ thesis. University of Birmingham.

Kamarudin, R. (2013b). A Corpus-based Study on the Use of Phrasal Verbs by Malaysian Learners of English: The Case of Particle up. Learner Corpus Studies in Asia and the World Proceedings. Kobe: Kobe University. 255-270

Kamus Dwibahasa Oxford Fajar (edisi keempat). (2008). Selangor: Oxford Fajar Sdn. Bhd.

Littlemore, J. and Low, G. (2006). Metaphoric competence and communicative language ability. Applied Linguistics 27(2), 268-294.

Longman Kamus Dwibahasa (edisi kedua). (2009). Selangor: Pearson Malaysia Sdn. Bhd.

Parkinson, D. (2001). Oxford phrasal verbs dictionary for learners of English. Oxford: Oxford University Press.

Side, R. (1990). Phrasal verbs: sorting them out. ELT Journal 44(2), 144-152.

Summers, D. (1988). The role of dictionaries in language learning. In R. Carter and M. McCarthy (eds.). Vocabulary and Language Teaching. London: Longman. 111-125

Zarifi, A., \& Mukundan, J. (2014). Creativity and Unnaturalness in the Use of Phrasal Verbs in ESL Learner Language. 